de 150 quilômetros, para os portos marítimos, há de ser contada sôbre o litoral a partir do porto extremo dos limites nacionais ao norte e ao sul.

Resumindo: a única restrição imposta atualmente às emprêsas de mineração decorrerá de estarem localizadas na faixa de fronteira, não por serem emprêsas de mineraçã̃o, e sim por serem indústria ali situada.

Fora dêsse caso, a lei ordinária não pode opor outras restrições à admissão de sócios estrangeiros nas emprêsas aludidas, pois, como ficou demonstrado, o texto constitucional vigente tem por fim exatamente atrair êsses capitais. Se o fizesse, antes que o Brasil não mais necessitasse dêles ou sem que graves exigências da defesa nacional assim aconselhassem, o legislador estaria contrariando e mesmo anulando o objetivo colimado pela Constituição. Brasil.

$O$ item quarto indaga se o acionista estrangeiro deve residir no

A resposta a êste está contida na do item anterior. Além da restrição apontada, que decorre de estar a indústria situada em zona considerada essencial à defesa nacional, nenhuma outra a Constituição vigente consignou às emprêsas de mineração.

E a de residência do acionista estrangeiro no Brasil seria a menos plausível. Concedendo a exploração de minas, jazidas, etc., sòmente a emprêsas organizadas no Brasil, visou a Constituição assegurar a fiscalização dos seus serviços e operações sem possibilidade de atrito com potências estrangeiras.

Brasileira sendo a emprêsa, sujeita está integralmente e exclusivamente ao direito brasileiro, pouco importando a nacionalidade e o domicílio de seus associados. Em caso de emergência, o art. 146 acima citado arma o poder público de remédios eficazes.

Atrair capital estrangeiro não quer dizer atrair estrangeiros para o Brasil. O que se quer é a cooperação financeira, necessária na fase atual da nossa evolução. Se, para isso, fôsse exigida a residência, aquela cooperação seria escassa, quase nula mesmo. Estaria prejudicada a finalidade do preceito constitucional, sem que para isso ocorressem motivos ponderáveis.

Com efeito. Do ponto de vista da segurança nacional, uma vez que a Constituição permite a participação de estrangeiros nas referidas emprêsas, pouco importaria que êles residissem ou não no Brasil. A fiscalização, a regulamentação é exercida sôbre a emprêsa, como pessoa jurídica brasileira, sujeita às sanções da lei brasileira.

Do ponto de vista econômico, a exigência de domicílio no país visaria sòmente evitar a saída de dividendos. Não é certo que o evitasse; mais certo, sem dúvida, é que não viessem capitais estrangeiros.

A estas razões específicas juntam-se as já aduzidas anteriormente, e tudo leva à conclusão de que não é necessário que o acionista estrangeiro resida no Brasil.

\section{ASPECTOS DO RECONHECIMENTO DA FILIAÇÃO ILEGÍTIMA}

Efeitos do ato ou da sentença que declara a filiação com base na Lei n. 883, de 21 de outubro de 1949, em relação à herança deferida antes da sua vigência.

\section{Sílvio Walace Duncan}

Tem-se dito e redito que, face ao preceito contido no artigo 1.577 do Código Civil, não podem os filhos ilegítimos alcançar a herança dos pais, se aberta a sucessão antes da vigência da lei permissiva do reconhecimento, eis que "a capacidade para suceder é a do tempo da abertura da sucessão, que se regulará conforme a lei então em vigor". Os que assim pensam, e são maioria no Brasil, afirmam que à solução contrária importaria na postergação do direito adquirido pelos herdeiros existentes ao tempo da abertura da sucessão, com se admitir efeito retroativo à lei que faculta o reconhecimento da filiação. Será exata a assertiva?

A matéria resume-se a uma questão de direito, objeto de renhida controvérsia. No País, tem foros de clássica a decisão do colendo Supremo Tribunal Federal, proferida, em grau de recurso de embargos, no caso da menor Colombina, que suscitou encômios ou censuras de eminentes juristas pátrios, consoante o ponto de vista adotado por uns e outros. Antes, a controvérsia apaixonara jurisconsultos de tomo, em França, ao se aplicar a lei de 16 de novembro de 1916. Em três sucessivos arestos, a Côrte de Cassação de Paris decidia que os filhos naturais reconhecidos podiam concorrer à sucessão dos respectivos pais, embora deferida antes de vigorar aquela lei. Esta solução, no entender do Tribunal Gaulês, não importava em ofensa aos direitos adquiridos pelos herdeiros existentes à época da abertura da sucessão, inobstante haver em França dispositivo idêntico ao do art. 1.577 do nosso Código, com proclamar que a capacidade para suceder é regulada pela lei em vigor no dia em que a sucessão se abre. 
Os argumentos expendidos pelos notáveis arestos serviram de guarida à decisão do caso Colombina (ver Crítica Judiciária, v. I ps. $334 / 356$ ), proporcionando os votos antagônicos dos eminentes ministros Godofredo Cunha e Hermenegildo de Barros.

A discussão ainda desafia a ponderação dos juízes e juristas, porque se exorna de fundo moral de inocultável relêvo, e a lei é de ser entendida de harmonia com o pensamento ético do povo, cuja conduta ela regula.

A legislação, passo a passo, evolui no sentido de proteger os frutos de ligações irregulares.

Os filhos ilegítimos, que por preconceito claudicante e injusto, eram as únicas vítimas dos erros dos pais, vão conquistando, na sociedade, o lugar que a natureza lhes assina.

Em tempo não muito remoto, premiava-se o infrator da moralidade familiar, o adúltero, com uma irresponsabilidade chocante, desvinculando-se-o de qualquer obrigação para com a prole havida fora do matrimônio. Prestava-se homenagem à família provinda de justas núpcias, preservando-se de escândalos a sua honra, que um dos cônjuges não soubera prezar, levado pelos desregramentos do sexo. Só o filho gerado das relações pecaminosas pagava o mal de ter vindo ao mundo! Era tão odiosa a injustiça que contra ela investiu o pensamento jurídico-filosófico da idade moderna, com fundamento no direito natural e na moral do cristianismo.

No Brasil, a campanha produz resultado em 1917, com a faculdade de reconhecimento dos filhos naturais in specie. Depois, a Carta Constitucional de 1937 recomenda a igualdade dos filhos legítimos, legitimados e naturais. Em 1942, faculta-se ao filho de desquitados o reconhecimento da paternidade. E, alfim, pela Lei n. 883 , de 1949 , num passo decisivo, proclama-se aquêle direito a todos os filhos havidos fora do matrimônio, uma vez dissolvida a sociedade conjugal dos pais.

Sabemos todos que o ato, ou a sentença de reconhecimento da filiação só produz efeitos declaratórios.

Desvelada a filiação, retrotrái a situação jurídica do fillho. Não ocorre a retroatividade da lei permissiva do reconhecimento, porque defesa, e a proibição foi erigida em cânon pela Constituição Federal de 1946, reatando-se a tradição jurídica nesse particular.

Os efeitos do reconhecimento é que são retro-operantes, quer seja êle voluntário quer judicial (art. 336 do Código Civil), e, por isso, adverte Maximiliano:

"a sentença (e nós ajuntamos: o ato) não constitui o estado do filho; não tem efeito atributivo, porém declarativo: declara uma qualidade ou condição preexistente, tendo seu fundamento na própria nạtureza".

Revista da Faculdade de Direito de Pôrto Alegre

Em tal tema supomos não haver divergência; tenta-se, porém, iludi-lo com se afirmar que dos efeitos deve ser eliminado o referente à di-lo com se afirmar que dos elc sucessão do pai, ou da mãe, sé aberta quando o tilho não te herdar é cidade para ser reconhecido; isso, porque a capacidade de herantam regulada pela lei vigente ao tempo da abertura da sucessa que, de outro modo, ir-se-á ferir o direito adquirido pelo herderro preexistente.

Data vênia, embora impressione, e venha arrimado à copiosa jurisprudência, o argumento é falho.

O efeito retro-operante é do ato ou da setença de reconhecimento, da A capacidade para herdar se funda, na hipótese, em a própria natureza, ou seja, na qualidade de filho, que a sentença ou o ato primplesmente declara.

A regra do artigo 1.577 do Código Civil diz ùnicamente respeito à A ressarte, não podia o cônjuge supérstite ordem de vocação herécice do pré-morto se a sucessão ocorresse antes da reclamar a herança do pré-mor

que o preferiu aos colaterácie, sendo descendente, guardou sempre a

O tilho de qualquer hereditária. O reconhecimento, uma vez admitisua posição na ordem hereditária. O reconhecimento, uma víz a direito do por lei, não cria mas tão-sòmente manifesta a filiação, como qualidade de recolher a herança paterna ou materna, posto

de descendente, seria êle o chamado à sucessão.

Já o Código Civil, estatuindo a respeito, dispunha que aquêle que vindicasse o reconhecimento da filiação, depois de dissolvido o mato legímônio do pai, teria, na partilha, tratamento identico ao dos na constântimos ou legitimados, mas, se o reconhecimento ocorresse na constancia do casamento, só à metade do que coubesse aquele teria direito o filho natural ( $\operatorname{art} .1 .605 \$ 1 .^{\circ}$ ). Pouco importa que o dispositivo tenha sido modificado.

A tese nêle exposta, com referência aos efeitos do reconhecimento, permanece de pé, mais viva que nunca.

uma prova de relação de paA lei todo o ato declarativo.

O reconhecimento, repete-se, tão-sòmente certifica a existência filiac̃o, que era oculta se se tratava de prole espúria.

Mas, com o advento da Lei n. 883, todos os filhos havidos fora do Mas, com o advento dêis dêste dissolvido, deixam de ser adulterinos, passando a naturais.

Assim entendeu o legislador ao dispor sôbre os filhos de desquita-

dos, como se verifica da exposição de motivos do Dec.-Lei n. 4.737.

“Atendendo à lei e ao pensamento do legislador, a jurisprudência passou a considerar simplesmente naturais os filhos de cônjuges desquitados, exigindo, porém, que tais 
filhos tenham sido concebidos após o desquite, ou, pelo menos, após a separação homologada por ato judicial. Não parece, entretanto, que haja motivo para a restrição. A jurisprudência citada declara que dissolvida a sociedade conjugal, pelo desquite, não há mais filhos adulterinos; ora se está no desquite o motivo para tirar o carácter de adulterinidade à prole nascida fora do casamento, parece não se justificar que tal efeito se produza sòmente quanto aos filhos posteriores ao desquite. Em primeiro lugar, dissolvida a sociedade conjugal, o reconhecimento já não importa em injúria ao cônjuge desquitado. Em segundo lugar, a ampliação aos filhos anteriores está exatamente em consonância com os artigos supracitados da Constituição".

É preciso se atentar que, depois da dissolução do casamento, desaparecendo a adulterinidade, o reconhecimento há de surtir todos os efeitos, inclusive sucessórios, a menos que a herança tenha sido deferida a outros há mais de trinta anos.

O Dr. Wagner Barreira, advogado nos auditórios de Fortaleza, publica em “Direito”, v. 57, correspondente aos meses de maio e junho de 1949, notável trabalho, para o qual chamamos a atenção dos estudiosos - porque, ao nosso sentir, responde às objeções dos que se colocam à ilharga do direito adquirido, para restringir os direitos dos filhos ilegítimos tocante à sucessão do pai, ou da mãe, quando aberta antes da lei facultativa do reconhecimento.

A lei que dispõe sôbre o estado das pessoas é de ordem pública e se aplica a quantos se encontrem na situação por ela regulada.

A de número 883, facultando o reconhecimento depois de dissolvida a sociedade conjugal do genitor, ou genitora, produz efeitos ex-tunc, dêsde a concepção do filho, sem a indicada restrição.

Regista o Dr. Wagner Barreira as vacilações do próprio Supremo Tribunal para, citando voto do doutíssimo Orozimbo Nonato, contrário à tese exposta, demonstrar o equívoco em que labora o grande juiz e os que lhe vão à esteira. Confessamos que também andáramos naquela trilha. Mas lícito será, por certo, a mudança de opinião, se nos convencemos de enganosos os conceitos e perspectivas que lhe servem de arrimo.

A mudança, nesse caso, vale por um reajustamento de balisas, que a meditação e o estudo comprovam imprestáveis à finalidade do instituto.

Nenhuma versatilidade, ou interêsse, impele-nos para o novo rumo.

A lei 883 deve ser interpretada teleològicamente, à luz da evolução política e social.

Nota-se ainda a preocupação de transigir com os preconceitos que falsearam, por tão largo tempo, a situação do filho gerado fora do casamento. O legislador não se libertou dêle, com denominar de amparo social a heranca que atribui aos filhos, nas condições previstas pela lei 883 , o que pode gerar confusões e criar situações falsas.

Cabe ao Judiciário alimpar a lei de dúvidas que contravenham a finalidade, com os olhos voltados para a advertência de Eurico Cimbali:

“O direito sagrado à vida nos indivíduos humanos que nascem, e a obrigação igualmente sagrada, para os pais que o põem no mundo, de fornecer-lhes os meios necessários à vida não são, não podem ser duvidosos, tratando-se de dar uma alta e improrrogável satisfação às leis e à suprema necessidade da natureza". 